\title{
The Influence of Female Characters on Consumers' Purchase Intention in RPG Games The research on how female characters influence consumers' purchase intention
}

\author{
DOI: $10.46932 / \operatorname{sfjdv3n1-091}$
}

Received in: Jan 30st, 2021

Accepted in: Feb 1th, 2022

\author{
Tianle Ye \\ College of Letters \& Science \\ University of California, Santa Barbara, Santa Barbara CA93106, United States. \\ E-mail: tianleye@ucsb.edu
}

\begin{abstract}
The characteristics of female roles, like beauty, background story, and behaviors, in RPG games have a great impact on consumers' consumption behavior. When the type of female characters is more popular with consumers, the sales of this game will be higher. Through investigation and research, the beauty of female characters has the greatest impact on consumers' purchase intention, while the behavior of female characters has the least impact on consumers' purchase intention.
\end{abstract}

Keywords: RPG female role, consumers' willingness of consuming, game selling.

\section{INTRODUCTION}

RPG is the role-playing game, which creates a virtual world for players to explore. With the fast development of the games' market, the RPG game has been greatly developed in the decades since its birth. Nowadays, RPG has become a major category in the game field, with a large number of loyal and high spending fans all over the world, so it contains a huge economic and cultural market. In 2019, China's RPG game market reached 71.94 billion yuan, and the growth rate of the market scale reached 18.29\%. Also, as Yang yuan's research shows, players prefer playing RPG in the choice of game types [4]. How to use the shaping of character art to bring sublimation to the game and increase the sales of the game has become a problem that RPG game manufacturers have to face. This article studies whether the shaping of a female role in RPG Games affects, how, positive or negative, and to what extent it affects consumers' desire to buy RPG Games. Also, this study can help game developers, designers and researchers better understand their consumers' minds and expand their markets.

\section{LITERATURE REVIEW}

The reality is not perfect. In this fast-paced world, everyone has more or less survival pressure, but the game world is always ideal and diverse [2]. In reality, we are limited everywhere because of jobs, 
family, or school, but in the game world, we can fly freely and find our true self in the game world. People always look for the shadow of reality in games, especially RPGs. As Xiang Lin said in the identity and aesthetic Carnival of playing online game players: "when people live in the dual space of reality and virtual, based on an ontological level of" who am I "and" what makes me me ", "The loss of subjectivity leads to an identity crisis and individual confusion, and the reconstruction of subjectivity has become an important topic. Acting online games provide an important path for the reconstruction of subjectivity in cyberspace, and can also construct an ideal identity in virtual space"[1]. As we immerse ourselves in the game, we will find that we not only establish our own identity in the game but also substitute our understanding of the world and aesthetics into the virtual game world. In other words, in some extents, we treat those fictitious worlds as the real world. Therefore, we sometimes have deep feelings for the role of the game in the game and begin to pity her, like her, and be attracted by her characteristics, and those emotions will arouse our desire for shopping.

\section{CLASSIFICATION AND RESEARCH ON FEMALE ROLE CHARACTERISTICS}

The beauty of women is diverse and complex. Just like Wu Qinghao said, "It not only needs a distinct and exquisite external image but also needs to contain certain cultural aesthetic characteristics" [3]. Although appearance factors are one of the main reasons for female roles in RPG Games, internal factors can also determine whether consumers like this female role, and these internal factors include their background story and personality. For example, compared with her excellent appearance, the popular character Kai'Sa in the League of Legends is popular among players because Kai'Sa is an independent, strong, and kind female soldier. The factors that determine the sales of games by a female role are very complex, so this paper will classify and study the characteristics of female characters in each best-selling game, such as beauty, background story, temper, behavior, and story development. Through the study of the impact of the above characteristics on the purchase intention of game consumers, a questionnaire survey is conducted to conclude.

\section{CLASSIFICATION OF RESPONDENTS}

After data acquisition, the respondents will be classified according to their age, income, gender, disposable income (salary for those with income and pocket money for those without income), time spent playing RPG games every day, and whether they are willing to spend on the game. Respondents who spend more money and have more passion for RPGs are classified as A group, and those who spend less money and have less passion are classified as B group, and the responses of A group have more influence on the results. 


\section{GAME DATA SOURCE WEBSITE}

After investigation, the data provided by VGChartz can best meet the needs of research because VGChartz's data is basically from official data which updated every week, so the data has high reference and timeliness. We selected 10 games from vgchartz and the selection criteria are: have a high degree of topics and downloads and have distinctive female roles. Super Mario (3386.29 million), pokemon (4380 million), final fantasy (including final fantasy 14 and final fantasy 15), final fantasy (200.00 million), Assassin's Creed series Assassin's created (13155.0 million), biochemical crisis (including biochemical crisis 6, biochemical crisis 7 and biochemical crisis 8), Resident Evil (17117 million) The legend of Zelda (19114.52 million), Tomb Raider Tom Raider (22,84 million) and God of War (49,51 million) are selected because these 10 games are very popular in their period and the female characters in these 10 games are very characteristic[6]. Some of the female characters are brave, positive, and determined, while others are intellectual and beautiful. However, most of the games' female characters have very clear characteristics.

\section{DATA COLLECTION}

This paper uses the spjump as the data collection tool, and the questionnaire collection time is 3 days. The first few questions will classify the respondents according to their age, gender, income, understanding of RPG Games, length of playing games, and the time that can be spending on games. The next questions are highly related to specific female characters in games that were selected according to the data from VG charts. Respondents answered these questions to express their views on the female roles in these 10 RPG Games and selected the biggest factors affecting their game purchase choices. The total number of respondents was 269. The interviewees come from all levels of society, such as students, employees, and freelancers. The questionnaire investigated the respondents' consumption ability and willingness to spend on games.

\section{DISCUSSION OF DATA}

After collecting 269 questionnaires, we found that the vast majority of respondents agreed that female characters in RPG Games had a more or less impact on their willingness to buy games, and they all said that they had the experience of buying a game because of a female character, and they all had a certain economic ability to consume games. 148 respondents were male, accounting for $55.02 \%$ of the total; 121 people are women, accounting for $44.98 \%$ of the total, indicating that the gender structure proportion of the respondents is reasonable. $75.09 \%$ of the respondents are office workers and $17.47 \%$ are students, and most of them know or know what RPG (role-playing games) is (accounting for 95.54\% of the total respondents). Most of the respondents have certain game consumption-ability (the largest number 
of people with a monthly income range of 5000-10000, accounting for 41.26\%) and most of them are willing to spend more than 50 yuan on games every month $(27.88 \%$ of the respondents willing to spend 50-100 yuan per month and $27.14 \%$ of the respondents willing to spend 100-200 yuan per month). It shows that most of the respondents know about RPG Games, and most of them have certain purchasing power.

In the following questionnaire, the impact of women's role on respondents' consumption intention is investigated. $83 \%$ of respondents believed that the design of female characters in RPG Games had an impact on their willingness to consume games, and $76.96 \%$ of the people had the experience of buying games for female characters, indicating that the design of female characters did have an impact on consumers' purchase intention. The next questionnaire question focuses on what characteristics of women's roles have the greatest impact on consumers' purchase intention. According to the questionnaire, appearance has the greatest purchase intention for consumers, accounting for $85.87 \%$ of the total respondents, while the impact on the development of the story plot, background story, and strength accounts for $57.99 \%, 52.42 \%$, and $52.42 \%$. The following survey on the preferences of specific female characters in specific games also proves this - in this question, respondents have to answer which specific female character is their favorite female character. Ada Wong, Alice in the Resident Evil and Laura in the Tomb Raider got the most preference from consumers, accounting for $21.56 \%$ and $18.59 \%$ respectively, and both of them have the characteristics of high appearance, attractive background story, great influence on the plot, extremely strong strength, and so on. However, the survey also shows that the behavior of female character has the least impact on people's purchase intention - only $27.51 \%$ of respondents said that what female characters do influence their choice of buying the game.

\section{CONCLUSION}

According to the data obtained from the questionnaire, we can conclude that female characters in RPG games have a great impact on players' willingness of consuming. Under the same quality and sales range, a female character with characteristics like great appearance, independence and high relevance to the game plot is more popular with game buyers, and the sales of games with such female characters will be higher than those of other RPG Games. Among them, the appearance of female characters has the greatest impact on consumers' purchase intention, while personality, background story, influence on the development of story plot, and strength also have an impact on consumers' purchase intention. In the choice of game role tendency, most people also choose the female role with the above characteristics as their preference. In this article, 
However, the game sale market is also influenced by the design of male characters because more and more women players have entered the world of RPGs. To further improve the sales of RPGs, game companies should also consult the results of male character's influence on people's purchase intention. 


\section{REFERENCE}

[1] Lin, Xiang. "Identity and aesthetic Carnival of online game players". Wuhan University of Technology (Social Science Edition). Vol.3, No.3. May 2016. Accessed on 7 Sept 2021.

[2] Shengzhi, Liu. "Gender concept in video games and its potential impact on Teenagers." Qing Nian Wen Hиа. DOI: 10.19633/j.cnki.11-2579/d.2012.08.015. Accessed on 7 Sept 2021.

[3] Qinghao, Wu. "Analysis on the artistic characteristics of game role setting in role-playing games." China Academic Journal Electronic Publishing House. https://www.cnki.net. Accessed on 8 Dec 2021.

[4] Yuan, Yang, "Design and Research on female characters in next generation games". Theoretical Discussion. Accessed on 8 Dec 2021.

[5] Yifang, Zhang. "Research on the influence of female image in video games on users' willingness to continue to participate". Journal of Changjiang Normal University. Vol2, 2021,37(02). DOI: 10.19933/j.cnki.ISSN1674-3652.2021.02.004. Accessed on 8 Sept 2021.

[6] VGChartz. https://www.vgchartz.com/gamedb/games.php?name=game. Accessed on 9 Sept 2021. 